\title{
Predicting potential graft rejection in renal transplant patients: data mining approach
}

\section{Dr. M.M. Hapudeniya}

Postgraduate Institute of Medicine, University of Colombo, Sri Lanka.

\author{
Dr. Rikaz Sheriff \\ Postgraduate Institute of Medicine, University of Colombo, Sri Lanka.
}

\section{Prof. R. Sheriff}

Postgraduate Institute of Medicine, University of Colombo, Sri Lanka.

Contact e-mail address: mmhapudeniya @ gmail.com

eHealth Sri Lanka 2010,1(suppl.1):S35

DOI: http://dx.doi.org/10.4038/sljbmi.v1i0.3598

Only the Abstract is available

\begin{abstract}
Renal transplantation (RT) is the organ transplant of a kidney into a patient with end-stage renal disease. In Sri Lanka, kidney is accepted from a living donor typically from a genetically related person. RT is a major surgical procedure and several investigations are done in order to assess the fitness and the compatibility of the graft with the patient. Transplant rejection is one of the major complications where the transplanted kidney is not accepted by the body of the recipient. Chronic transplant rejection is irreversible and cannot be treated effectively.

It is very important to predict the possibility of the graft rejection as the decision for undergoing a RT is one of the major decisions the patient will make. This further helps to improve post operative management and long term care of the patient. We explored the possibility of developing a simpler, equally accurate and more user friendly model to predicting the potential graft failure using data from renal transplantations done at a leading private hospital in Sri Lanka. The results predicted by the model were evaluated against the prediction of experienced clinicians to assess its accuracy and effectiveness.
\end{abstract}

Keywords - graft rejection, renal transplant patients, data mining, transplant rejection 